\title{
PENGARUH PENGGUNAAN MEDIA ABAKUS TERHADAP KONSEP BERHITUNG MATEMATIKA PENGURANGAN DAN PEMBAGIAN PADA ANAK TUNANETRA KELAS IV SLB-A TPA JEMBER
}

\author{
Theresia Irmina, Lailil Aflahkul Yaum M.Pd \\ PLB IKIP PGRI Jember \\ email: theresiairmina1290@gmail.com
}

\begin{abstract}
Abstrak
Penelitian ini bertujuan untuk mengetahui pengaruh penggunaan media abakus terhadap konsep berhitung matematika pengurangan dan pembagian anak tunanetra kelas IV SLB -A TPA Jember. Penelitian ini menggunakan metode Subject Research (SSR) dengan desain A-B Subject penelitian ini siswa tunanetra inisial J. Penelitian ini dilakukan sebanyak 10 sesi pertemuan yang dilakukan pada dua fase yaitu 4 sesi fase baseline (A) serta 6 sesi fase intervensi (B). Hasil penelitian ini menunjukkan adanya pengaruh media abakus terhadap konsep berhitung pengurangan dan pembagian pada anak tunanetra hal ini ditunjukkan dengan data nilai yang diperoleh pada fase baseline (A) adalah 31,25\%, 37,5\%, 37,5\%, dan 43,75\%. Sedangkan pada fase intervensi (B) antara lain 87,5\%, 87,5\%, 87,5\%, 87,5\%, 93,75\%, 93,75\%. Dari data yang diperoleh kemudian dianalisis menggunakan analisis dalam kondisi dan analisis antar kondisi. Hasil data analisis dalam kondisi serta analisis antar kondisi menunjukkan bahwa mean level fase baseline (A) yaitu 37,5\% sedangkan fase intervensi mean level (B) 89,58\%, serta selisih perubahan level dari fase baseline (A) sanpai fase intervensi (B) yaitu meningkat (+43,75\%). Dengan Perubahan kecenderungan arahnya adalah meningkat dan presentase overlap 0\%. Maka diketahui bahwa adanya pengaruh penggunaan media abakus terhadap konsep berhitung pengurangan dan pembagian terhadap konsep berhitung matematika pengurangan dan pembagian pada anak tunanetra kelas IV Di SLB -A TPA Jember.
\end{abstract}

Kata Kunci : Tunanetra, media abakus, konsep berhitung matematika pengurangan dan pembagian

\section{PENDAHULUAN}

Tunanetra umumnya adalah seorang anak yang mengalami hambatan dalam penglihatan baik itu total maupun buta sebagian (low vision) yang berhubungan dengan indra penglihatan atau visual sehingga menyebabkan anak mengalami keterbatasan dalam kegiatan sehari-hari. National Healt Service menjelaskan bahwa gangguan penglihatan individu yang mengalami kebut aan total atau buta sebagian (Thompson, 2012, hlm. 12).
"Dampak seseorang mengalami ketunanetraan adalah sulitnya menerima materi atau informasi yang diberikan secara visual dan berdampak pada keoptimalan proses kegiatan pembelajaran salah satunya adalah pembelajaran matematika, anak tunanetra mengalami kesulitan dalam berhitung terutama dalam pengurangan dan pembagian dikarenakan kurangnya media untuk mempermudah siswa dalam mengikuti pelajaran dan terlihat pasif. 
Kemampuan hitung anak tunanetra sangat rendah hal ini disebabkan oleh beberapa faktor yaitu kurangnya latihan operasi hitung, penyajian yang monoton, kurang variatif, situasi dan kondisi yang kurang mendukung pada proses belajar mengajar serta penggunaan media pembelajaran kurang tepat herwanto (dalam Hartono, 2017, hlm. 2) Agar proses interaksi komunikasi edukatif antara guru dan siswa dapat berlangsung secara tepat guna dan berdaya guna maka dibutuhkan media yang tepat. Menurut Mais (2016, hlm. 9) mengatakan media pembelajaran sebagi penyalur pesan antara guru dan siswa agar tujuan pengajran tercapai. Salah satu media yang dapat berfungsi untuk meningkatkan pembelajaran matematika adalah media abakus.

Abakus merupakan alat yang cukup praktis digunakan dalam pelajaran matematika tidak hanya siswa awas, akan tetapi juga dapat digunakan oleh siswa tunanetra. Abakus yang digunakan siswa tunanetra merupakan abakus yang sama digunakan oleh siswa awas. Menurut Sumini (dalam Herwanto, 2013, hlm. 4) menjelaskan bahwa alat hitung abakus dapat meningkatkan prestasi belajar matematika siswa tunanetra.Untuk mengoptimalkan media yang digunakan anak tunanetra maka diperlukan modifikasi media dengan menggunakan tulisan braille dan memberikan deretan angka pada abakus. Hal ini menjadi dasar bahwa dengan menggunakan media abakus yang telah di modifikasi maka dapat membantu siswa tunanetra dalam mengikuti proses pembelajaran dan memudahkan penerima pesan menerima suatu konsep.

Berdasarkan hasil observsi yang dilakukan di SLB-A TPA Jember ditemukan permasalahan terkait dengan pembelajaran matematika. Hal ini didukung dengan hasil bahwa siswa tunanetra belum mampu soal operasi hitung pengurangan dan pembagian contohnya $8-2=6$ dan $8: 2=6$, siswa juga terlihat pasif dan kurang bertanya tentang materi pengurangan dan pembagian ini disebabkan kurangnnya media yang digunakan pada saat pembelajaran berlangsung, guru hanya menggunakan alat hitung jari sehingga siswa terlihat bosan dan pembelajarannya kurang optimal. Hal ini menjadi bahan pemikiran pendidik dalam mencari solusi supaya pembelajaran pengenalan konsep berhitung pengurangan dan pembagian dapat berhasil disampaikan kepada siswa tunanetra dan mencapai kompetensi yang diharapkan dengan mengunakan media abakus. 
Karena berbagai penyebab diatas maka pembelajaran konsep berhitung pengurangan dan pembagian di SLB-A TPA Jember khususnya dikelas IV SD perlu diperbaiki baik dalam strategipembelajaran maupun media pembelajaran yang digunakan. Strategi pembelajaran yang harus dilakukan oleh guru dalam menyampaikan pesan atau materi pembelajaran agar tujuan pembelajaran dapat tercapai. Maka peneliti menggunakan media abakus yang dimodifikasi braille angka.

\section{METODE}

Penelitian ini menggunakan metode penelitian subjek tunggal (single subject research) Menurut Ronsnow (dalam Sunanto, 2005:54) desain penelitian single subject design adalah suatu penelitian eksperimen pendekatan kuantitat if. Pengukuran yang digunakan dalam penelitian ini adalah presentase dengan periode waktu tertentu misalnya perjam, perhari, atau perminggu. Hasil pengukuran tidak dibandingkam dengan subject lainnya tetapi dibandingkan degan subject yang sama tetapi ada kondisi yang berdeda. desain yang digunakan pada penelitian ini yakni desain A-B . prosedur desain ini disusun atas
Media abakus yang dimaksud peneliti berbentuk persegi panjang dengan jumlah batangnya ada 5 (lima) tiang pemisah yang setiap tiang terdiri dari sepuluh manik- manik dan dimodifikasi menggunakan braile angka dan belakangnya diberi tulisan awas agar lebih memudahkan siswa tunanetra dalam belajar. Diharapkan dengan menggunakan media abakus dapat mengkongkretkan pemahaman siswa tunanetra terhadap konsep berhitung pengurangan dan pembagian.

dasar apa yang di sebut logica baseline (Baseline Logic). (sunanto,2005 hlm:55) mengatakan logika baseline merupakan suatau pengulangan pengukuran perilaku atau targer behavior sekurang- kurangnya 2 kondisi yaitu kondisi baseline (A) dan kondisi intervensi (B).

Desain A-B tidak ada pengulangan atau replikasi pada fase baseline dan intervensi dan hanya dilakukan sekali untuk subjek yang sama. Sunanto, (2005: hlm:55). Maka dalam penelitian subject tunggal desain A-B intervensi dan baseline hanya dilakukan satu kali penelitian yaitu dengan menggunakan media abakus dan variabel terikat dalam penelitian ini yaitu konsep 
berhitung pengurangan dan pembagian anak tunanetra kelas IV SD SLB-A TPA Jember.

Penelitian ini

dilakukan pada bulan juli dan agustus 2020 di SLB -A TPA Jember. subject penelitian ini siswa tunanetra kelas IV SD yang berusia 12 tahun dengan inisal J siswa kurang fokus, pasif dan belum memahami konsep berhitung pengurangan dan pembagian.

PeneLitian ini mengunakan instrumen test yang berfungsi untuk mengetahui sejauh mana $\mathrm{J}$ memahami konsep berhitung pengurangan dan pembagian, pengumpulan data dilakukan sebanyak 4 sesi baseline (A) dan 6 sesi intervensi (B).

$$
\text { Sunanto (2005, hlm.93) }
$$
singgel subject reasrt (SSR), data disajikan menggunakan statistik deskriptif yang berbentuk grafik. setelah data semua terkumpul, selanjutnya data dianalisis dengan perhitungan tertentu yang dapat dipertangung jawabkan. perhitungan ini dianaliasis dengan analisis yaitu analisis antar kondisi dan analisis dalam kondisi. hal tersebut dilakukan agar lebih mudah memahami data apakah ada penggaruh media abakus terhadap konsep berhitung matematika pengurangan dan pembagian anak tunanetra kelas IV SD SLB -A TPA Jember.

\section{HASIL DAN PEMBAHASAN}

Berdasakan hasil pengumpulan data dan analisis dapat dikemukakan beberapa hasil penelitian, penelitian ini didapat dari hasil presentase dengan menggunakan desain reselval AB. Adapun dua fase penelitiian yaiitu baseline (A) dan intervensi (B).

\section{Baseline (A)}

Pengambilan data pada fase baseline dilakukan sebanyak 4 sesi dengan nilai yang diperoleh $31,25 \%$, 37,5\%, 37,5\%, 43,75\%.

\section{Intervensi (B)}

Dilakukan setelah diperoleh data yang stabil mengenai kemampuan konsep berhitung matematika pengurangan dan pembagian yang didapat dari subject pada fase baseline, maka dapat dilakukan penelitian tahap selanjutnya yaitu pada fase intervensi dengan melakukan penelitian kemampuan konsep berhitung pengurangan dan pembagian dengan menggunakan media abakus. Adapun hasil penelitian dari fase intervensi (B) $87,5 \%$, 87,5\%, 87,5\%, 87,5\%, 93,75\%, 93,75\%. Dari data baseline (A) dan data Intervenvsi (B) dapat dibuat grafik sebagai berikut 
Grafik 1. Nilai Baseline dan Intervensi

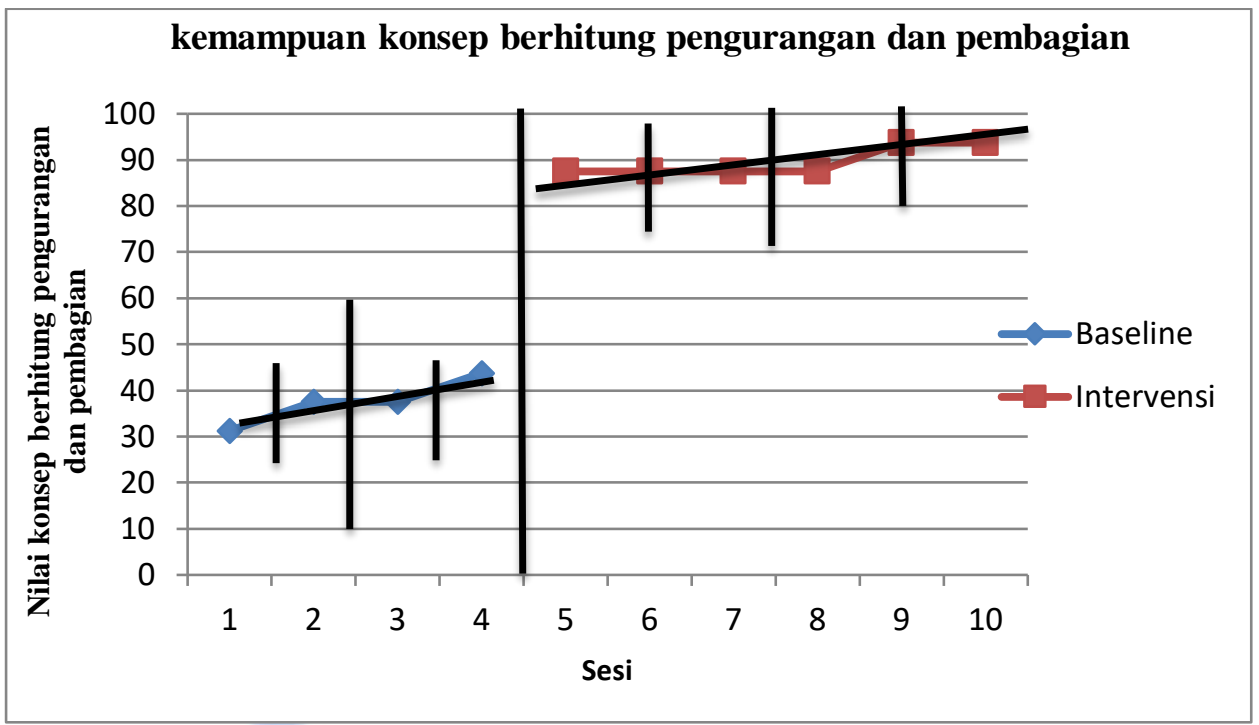

Tabe 1 Anlisis dcalam kocndisi

\begin{tabular}{|c|c|c|}
\hline Kondisi & $\mathrm{A} / 1$ & $\mathrm{~B} / 2$ \\
\hline \multicolumn{3}{|l|}{ Panjang Kondisi } \\
\hline \multicolumn{3}{|l|}{ Estimasi Kecenderungan } \\
\hline \multicolumn{3}{|l|}{ Arah } \\
\hline Kecenderungan Stabilitas & Variabel & Stabilitas \\
\hline & $50 \%$ & $100 \%$ \\
\hline \multicolumn{3}{|l|}{ Jejak Data } \\
\hline & $(+)$ & $(+)$ \\
\hline \multirow[t]{2}{*}{ Level Stabilitas dan Rentang } & $\underline{\text { Variabel }}$ & $\underline{\text { Stabil }}$ \\
\hline & $31,25-43,75$ & $87,5-93,75$ \\
\hline \multirow[t]{2}{*}{ Perubahan Level } & $\underline{43,75-31,25}$ & $\underline{93,75-87,5}$ \\
\hline & $(+12,5)$ & $(+6,25)$ \\
\hline
\end{tabular}

Tacbel 2. Anaclisis antfar kofndisi

\begin{tabular}{lc}
\hline Kondisi & $\mathrm{B}_{1} \mathrm{~A}_{1}$ \\
\hline Perbandingan Kondisi & $2: 1$ \\
\hline Panjang Kondisi & 1 \\
\hline
\end{tabular}


Esatimasi Kecenderungan Arah

$(+)$

$(+)$

\begin{tabular}{lc}
\hline Perubahan Kecenderungan Arah & Stabil ke Variabel \\
\hline Perubahan Level & $(43,75-87,5)$ \\
& $(+43,75)$ \\
\hline Presentase Overlap & $0 \%$ \\
\hline
\end{tabular}

Pada saat melakukan observasi dikelas IV SD di SLB A TPA Jember, terkait cara belajar dan penggunaan media pembelajaran untuk anak tunanetra dalam pelajaran memahami konsep berhitung matematika pengurangan dan pembagian. Hasil pembelajaran yang dilakukan oleh guru cenderung kurang maksimal. Guru kurang dapat memberikan pembelajaran yang menyenangkan atau monoton, karena kurang adanya media yang dapat mendukung proses pembelajaran, Sehingga siswa cenderung kurang tertarik dan cepat bosan terhadap pembelajaran yang diberikan oleh guru.maka dari hal tersebut untuk meningkatkan kemampuan konsep berhitung matematika pengurangan dan pembagian pada anak tunanetra dengan menggunakan media abakus yang dimodifikasi dengan braille angka.

Penelitian ini dilakukam sebanyak 10 sesi, yaitu 4 sesi baseline (A) dan 6 sesi intervensi (B) dalam setiap sesi dilakukan pada hari yang berbeda. pada sesi pertama baseline (A) J mendapatkan nilai 31,25\% dalam hal ini $\mathrm{J}$ cenderung bosan dan mengalihkan pembicaraan atau tidak menghiraukan yang membuat pembelajaran terhambat, sesi kedua dan ketiga $\mathrm{J}$ terlihat tergesa-gesa saat menjawab soal yang diberikan sehingga nilai yang didapatkan masih sangat rendah yaitu $37,5 \%$ pada sesi ke empat $\mathrm{J}$ mulai ada peningkatan dalam mengerjakan soal yang diberikan namun masih banyak yang kurang tepat atau salah sehingga mendapatkan nilai 43,75.\%

Pada fase Intervensi (B) dengan menggunakan media abakus terjadi peningkatan ini terlihat pada sesi kelima sampai kedelapan $\mathrm{J}$ mendapatkan nilai 87,5 pada sesi ini $\mathrm{J}$ mampu mengerjakan soal dengan baik dan tidak ada kendala yang dikarenakan sebelum fase intervensl $\mathrm{J}$ diberi pendekatan yang menbuat $\mathrm{J}$ tertarik dengan pembelajaran yang akan diberikan sedangkan pada sesi kesembilan 
dan kesepuluh J mengalami peningkatan sangat baik yang dimana $\mathrm{J}$ dapat menjawab soal yang diberikan dengan baik dan mendapatkan nilai 93,75\% Hal tersebut dikarenakan $\mathrm{J}$ mulai terbiasa berhitung konsep pengurangan dan pembagian dengan menggunakan media abakus. sehingga $\mathrm{J}$ dianggap cukup dalam fase Intervensi ini terbukti J mendapatkan nilai 93,75\% secara berturut-turut. kemampuan J pada fase intervensi memiliki nilai terendak $87,5 \%$ dam tertinggil 93,75\%.

Penggunaan media abkus dapat membantu J dalam memahami konsep berhitung pengurangan dan pembagian. hal ini terbukti dari hasil penelitian dimana terdapat perubahan kemampuan konsep berhitung pengurangan dan pembagian inl terlihat dari mean level pada fase baseline (A) yaiitu $37,5 \%$ sedangkam level mean pada fase intervensi $89,58 \%$. serta selisi perubahan level darl fase baseline sampai awali intervensi (B) meningkat (+ 43,75\%) selisih perubahan kemampuan $\mathrm{J}$ pada fase intervensi (B) mengalami peningkatan dari fase baseline (A) dengan menngunakan media abakus.

Dari pembahasan diatas maka dapat dibuktikan bahwa media abakus dapat berpengaruh terhadap konsep berhitung pengurangan dan pembagian pada anak tunanetra.

\section{PENUTUP}

Hasil penggunaan media abakus dapat membantu $\mathrm{J}$ dalam meningkatkan

kemampuan konsep berhitung matematika pengurangan dan pembagian. ini terbukti pada hasil penelitian, terjadi perubahan terhadap kemapuan konsep berhitung pengurangan dan pembagian siswa dengan menggunakan media abakus yang dimodifikasi menggunakan braille angka. ini terlihat jelas dari mean level fase baseline (A) sampal awal fase intervensi (B) meningkat $(+43,75)$ Selisi perubahan level kemampuan J pada fase Intervensi (B) mengalami peningkatan dari fase baseline (A) dengan mengunakan media abakus.

Dari hasil kesimpulam penelitian diatass maka pengunaan media abakus berpenggaruh dalam meninggkatkan kemampuan konsep berhitung matematika pengurangan dan pembagian pada siswa tunanetra kelas IV di SLBA TPA Jember tahun ajaraan 2019/2020.

\section{SARAN}

Setelah memperhatikan hasil yang diperoleh peneliti maka kesimpulan yang dapat dikemukakan, maka ada beberapa saran dalam penelitian ini yaitu 
(1) bagi peneliti selanjutnya, mengkaji menelaah dan mengadakan penelitian lebih lanjut tentang penggunaan media abakus terhadap konsep berhitung matematika pengurangan dan pembagian anak berkebutuhan khusus, khususnya anak tunnanetra (2) Bagi guru, agar dapat memanfaatkan dan mengembangkan media abakus dalam proses pembelajaran konsep berhitung matematika pengurangan dan pembagian agar dapat meningkatkan motivasi siswa dengan baik dalam mengikuti pelajaran. (3) Bagi sekoiah, agar dapat medukung dan mengmbangkan media abakus dengan menggunakan angka Braille yang nantinya dapat menunjang kemampuan anak dalam belajar dan mudah menerima materi yang berbubungan dengan konsep berhitung pengurangan dan pembagian.

\section{DAFTAR PUSTAKA}

Herwanto, Hartono. (2017). Pengaruh Media Abakus Terhadap Kemapuan Mengenal Operasi Hitung Bilangan Metematika Siswa Tunanetra Di SLB Negeri Praya. Jurnal Mahasiswa Unesa. Diakses 17 maret 2020

Maiz, Asrorul. (2016). Media Pembelajaran Anak Berkebutuhan Khusus, Jember: CV Pustaka Abadi

Sunanto, Juan, dkk. (2005). Pengantar Pendidikan Dengan Subjek
Tunggal. CRIED University Of Terbuka 